Gut, 1984, 25, 1291-1295

\title{
Correction of altered plasma amino acid pattern in cirrhosis of the liver by somatostatin
}

\author{
B LIMBERG AND B KOMMERELL
}

From the Department of Internal Medicine, University of Heidelberg, D-6900 Heidelberg, FRG

SUMmary The purpose of our study was to evaluate the effect of somatostatin $(500 \mu \mathrm{g} / \mathrm{h}$ intravenously) upon insulin, c-peptide, glucagon and plasma amino acids concentrations in patients with and without cirrhosis of the liver. The typical plasma amino acid pattern in cirrhosis is characterised by increased concentrations of the aromatic amino acids and decreased concentrations of the branched chain amino acids and of alanine and glycine. After administration of somatostatin insulin, c-peptide and glucagon concentrations decreased and those of the branched chain amino acids in both groups increased; in addition in patients with cirrhosis the plasma concentrations of threonine, serine, glycine, alanine, lysine, and arginine increased also. Infusion of somatostatin plus insulin in patients with cirrhosis succeeded in preventing the increase in the branched chain amino acid concentrations, while the infusion of somatostatin plus glucagon decreased threonine, serine, glycine, alinine, phenylalanine, tyrosine, lysine and arginine concentrations. It is therefore suggested that the effect of somatostatin on the plasma amino acids may be because of the reduction of insulin and glucagon concentrations; however, other effects of somatostatin cannot be excluded at present.

The existence of an altered amino acid pattern in the plasma of patients with advanced cirrhosis of the liver is well known. This pattern is characterised by an increase in the concentration of the aromatic amino acids tyrosine and phenylalanine and a decrease in the concentrations of the branched chain amino acids valine, leucine, isoleucine and of alanine and glycine. ${ }^{1-4}$ High concentrations of aromatic amino acids may be causally related to hepatic encephalopathy leading to accumulation of false neurotransmitter in the central nervous system. ${ }^{1}$ Attention has, therefore, been focused on the distorted free amino acid patterns in the plasma of the cirrhotic patient. The reasons for the altered plasma amino acid pattern have been still incompletely understood, but two factors have been thought to contribute to the development of plasma amino acid imbalance in cirrhosis. The protein catabolism is increased ${ }^{5}$ and the concentrations of insulin and glucagon are increased, $;^{6-8}$ it has been proposed that hyperglucagonaemia causes an increase of the aromatic amino acids and hyperinsulinaemia a decrease of the branched chain

Address for correspondence: Dr Bernd Limberg, Medizinische Universitätsklinik, Bergheimerstr. 58, D-6900 Heidelberg, FRG.

Received for publication 10 February 1984 amino acids. ${ }^{9}$ In contrast a direct correlation of decreased branched chain amino acids concentrations with insulin concentrations and of raised aromatic amino acids concentrations with glucagon concentrations has not been observed. ${ }^{10}$

Somatostatin is known to inhibit insulin and glucagon secretion in normal man. ${ }^{11}$ Somatostatin seems therefore to be a good medium for studying the inter-relationship between plasma amino acid and hormone imbalance. In order to elucidate this inter-relationship the influence of somatostatin on raised insulin and glucagon concentrations and on altered amino acid pattern in cirrhosis of the liver was investigated; moreover the effect of selective hyperinsulinaemia and hyperglucagonaemia on the plasma amino acid pattern was studied.

\section{Methods}

\section{SUBJECTS AND PATIENTS}

Ten male control subjects without liver disease and 10 male patients with histologically proven cirrhosis of the liver were included in this investigation. All patients had a history of excessive alcohol consumption; cirrhosis was regarded as the consequence of chronic alcoholism when no other cause of liver 
disease was shown. Upper gastrointestinal endoscopy revealed oesophageal varices in all patients. The patients were in stage Child $\mathrm{B},{ }^{12}$ the serum creatinine was normal and the transferases below $60 \mathrm{IU} / \mathrm{l}$ (normal: <24 IU/l). All patients were abstinent for at least 14 days. All subjects gave written informed consent. The study had been approved by the local ethical committee.

The investigation was performed after an overnight fast and rest. On day 1 after a bolus injection of $250 \mu \mathrm{g}$ somatostatin (Serono, Freiburg) somatostatin $(500 \mu \mathrm{g} / \mathrm{h})$ was infused intravenously for four hours. On day 2 somatostatin $(500 \mu \mathrm{g} / \mathrm{h}$ after a bolus injection of $250 \mu \mathrm{g}$ ) was administered together with glucagon $(45 \mathrm{nmol} / \mathrm{h})$ (Glukagon, Lilly) and on day 3 together with insulin $(11 \mathrm{nmol} / \mathrm{h})$ (Insulin, Hoechst) over the same time period. Blood samples were drawn before and 240 minutes after starting the infusion. Plasma amino acids, insulin, c-peptide and glucagon were determined in all samples. Plasma immunoreactive insulin was measured $^{13}$ using Sephadex bound antibodies (Phadebas, Pharmacia). C-peptide was determined ${ }^{14}$ by radioimmunoassay using a commercially available kit (Novo, Copenhagen). For the determination of plasma immunoreactive glucagon $4.0 \mathrm{ml}$ samples of blood were transferred to chilled tubes containing $0.2 \mathrm{M}$ EDTA- $\mathrm{Na}_{2}$ and $0.2 \mathrm{ml}$ aprotinin (Trasylol, Bayer). Plasma immunoreactive glucagon was determined using Unger's antibody $30 \mathrm{~K} .{ }^{15}$ Free plasma amino acids were measured by ion exchange chromatography on an amino acid autoanalyser (Biotronik) using norleucine as internal standard; the plasma was deproteinised by $6 \%$ sulphosalicylic acid. All samples were stored at $-20^{\circ} \mathrm{C}$ until analysed. Student's $t$ test and where applicable the paired $t$ test were used to determine statistical significance. Data are expressed as mean \pm SEM.

\section{Results}

In patients with cirrhosis of the liver the preinfusion concentrations of insulin and glucagon (Table 1) and of the aromatic amino acids tyrosine and phenylalanine were raised whereas the concentrations of the branched chain amino acids valine, leucine, isoleucine and of alanine and glycine were decreased when compared with controls (Table 2). No differences were seen in the concentration of c-peptide (Table 1).

Somatostatin infusion resulted in a significant decrease of insulin, glucagon and c-peptide concentration in both groups (Table 1). At the end of somatostatin infusion the concentration of the branched chain amino acids were significantly increased in both groups, while the concentrations
Table 1 Plasma insulin, c-peptide and glucagon concentrations in control and cirrhotic subjects in response to somatostatin $(500 \mu \mathrm{g} / \mathrm{h}$ after a bolus injection of $250 \mu \mathrm{g})$ administration for 240 minutes

\begin{tabular}{lcclll}
\hline & \multicolumn{2}{l}{ Controls $(10)$} & & \multicolumn{2}{l}{ Cirrhotics $(10)$} \\
\cline { 2 - 3 } \cline { 5 - 6 } \cline { 5 - 6 } & $0 \min$ & $240 \min$ & & 0 min & $240 \min$ \\
\hline Insulin $(\mathrm{pmol} / \mathrm{l})$ & $72 \pm 21$ & $21 \pm 14^{*}$ & & $259 \pm 86^{\dagger}$ & $93 \pm 28^{*}$ \\
C-peptide $(\mathrm{nmol} / 1)$ & $0 \cdot 4 \pm 0 \cdot 2$ & $0 \cdot 1 \pm 0 \cdot 05^{*}$ & $0 \cdot 55 \pm 0 \cdot 25$ & $0 \cdot 1 \pm 0 \cdot 05^{*}$ \\
Glucagon $(\mathrm{pmol} / \mathrm{l})$ & $21 \pm 3 \cdot 4$ & $12 \pm 1 \cdot 7^{*}$ & & $73 \pm 6 \cdot 6 \dagger$ & $50 \pm 10 \cdot 3^{*}$ \\
\hline
\end{tabular}

* Significantly different from basal values for the same subjects ( $p<0.01$ or less).

$\dagger$ Significantly different from basal values obtained in the control group ( $p<0.01$ or less).

of the aromatic amino acids remained unchanged (Table 2). In contrast with the controls somatostatin had an additional effect on the so called gluconeogenic amino acids threonine, serine, glycine, alanine, lysine, and arginine in patients with cirrhosis of the liver. Infusion of somatostatin led to a significant increase of these amino acids. The most prominent rise induced by somatostatin concerned the concentration of alanine, which reached normal values (Table 2).

The combination of somatostatin and glucagon in patients with cirrhosis led to a decrease of insulin from $230 \pm 70$ to $79 \pm 40 \mathrm{pmol} / \mathrm{l}$ and of c-peptide from $0 \cdot 6 \pm 0 \cdot 22$ to $0 \cdot 1 \pm 0.05 \mathrm{nmol} / \mathrm{l}(\mathrm{p}<0 \cdot 01)$, whereas the concentration of glucagon increased from $71 \pm 7$ to $229 \pm 28 \mathrm{pmol} / \mathrm{l}(\mathrm{p}<0 \cdot 001)$. In addition, the increase of the gluconeogenic amino acids induced by

Table 2 Plasma amino acids ( $\mu$ mol/l) in control and cirrhotic patients before and after infusion of somatostatin $(500 \mu \mathrm{g} / \mathrm{h}$ after a bolus injection of $250 \mu \mathrm{g})$ for 240 minutes

\begin{tabular}{|c|c|c|c|c|}
\hline & \multicolumn{2}{|c|}{ Controls (10) } & \multicolumn{2}{|c|}{ Cirrhotics (10) } \\
\hline & $0 \min$ & $240 \min$ & $0 \min$ & $240 \min$ \\
\hline Threonine & $83 \pm 24$ & $87 \pm 20$ & $80 \pm 20$ & $117 \pm 24^{*}$ \\
\hline Serine & $67 \pm 16$ & $71 \pm 17$ & $65 \pm 15$ & $95 \pm 23^{*}$ \\
\hline Glycine & $195 \pm 15$ & $190 \pm 20$ & $150 \pm 12+$ & $185 \pm 10^{*}$ \\
\hline Alanine & $235 \pm 10$ & $246 \pm 25$ & $161 \pm 35 t$ & $235 \pm 32^{*}$ \\
\hline Valine & $160 \pm 11$ & $216 \pm 12^{*}$ & $107 \pm 22 \dagger$ & $145 \pm 10^{*}$ \\
\hline Leucine & $122 \pm 8$ & $156 \pm 10^{*}$ & $63 \pm 10+$ & $104 \pm 9^{*}$ \\
\hline Isoleucine & $68 \pm 11$ & $90 \pm 13^{*}$ & $33 \pm 12+$ & $50 \pm 8^{*}$ \\
\hline Phenylalanine & $41 \pm 9$ & $50 \pm 10$ & $60 \pm 8+$ & $68 \pm 7$ \\
\hline Tyrosine & $55 \pm 10$ & $64 \pm 11$ & $90 \pm 9+$ & $99 \pm 12$ \\
\hline Lysine & $125 \pm 30$ & $130 \pm 15$ & $100 \pm 25$ & $140 \pm 20^{*}$ \\
\hline Arginine & $72 \pm 15$ & $80 \pm 12$ & $65 \pm 10$ & $100 \pm 10^{*}$ \\
\hline
\end{tabular}

* Significantly different from basal values for the same group ( $p<0.05$ or less).

+ Significantly different from basal values obtained in the control group ( $<<0.05$ or less). 
somatostatin alone was not observed. In contrast the concentrations of the gluconeogenic and aromatic amino acids decreased significantly (Table 3 ).

Infusion of somatostatin plus insulin led to a decrease of glucagon from $63 \pm 2 \cdot 8$ to $45 \pm 5 \mathrm{pmol} / \mathrm{l}$ and of c-peptide from $0 \cdot 65 \pm 0 \cdot 2$ to $0 \cdot 1 \pm 0 \cdot 05 \mathrm{nmol} / \mathrm{l}$ $(\mathrm{p}<0 \cdot 01)$, but the insulin concentrations remained raised $(129 \pm 21 \mathrm{pmol} / \mathrm{l})$. No increase of the branched chain amino acids was observed.

\section{Discussion}

In patients with cirrhosis of the liver high insulin concentrations have been documented. ${ }^{6}{ }^{16}$ Results from studies dealing with the plasma c-peptide concentrations are found to be conflicting; some authors reporting normal ${ }^{6717}$ and others increased concentrations of c-peptide. ${ }^{18}$ Insulin and c-peptide are secreted in equimolar amounts from the pancreatic cells. ${ }^{19} \mathrm{C}$-peptide is mainly metabolised in the kidney while insulin metabolism centres in the liver and in fat and muscle tissue. ${ }^{20}$ Normal concentrations of c-peptide in cirrhosis would therefore indicate that hyperinsulinaemia in cirrhosis is mainly because of a diminished degradation of insulin. ${ }^{67}$ On the other hand raised c-peptide concentrations would suggest the presence of insulin hypersecretion. ${ }^{18}$ In our patients with cirrhosis insulin concentrations were increased and c-peptide concentrations were normal. In both groups of patients (those with and without cirrhosis) the infusion of somatostatin initially resulted in a marked reduction of insulin and c-peptide concentrations. After the somatostatin infusion, insulin levels nonetheless remained raised in the patients with cirrhosis, while the c-peptide concentrations

Table 3 Influence of combined infusion of somatostatin $(500 \mu \mathrm{g} / \mathrm{h}$ after bolus injection of $250 \mu \mathrm{g})$ and glucagon (45 $\mathrm{nmol} / \mathrm{h})$ on plasma amino acids ( $\mu \mathrm{mol} / \mathrm{l})$ in patients with cirrhosis

\begin{tabular}{lcc}
\hline & $0 \min$ & $240 \mathrm{~min}$ \\
\hline Threonine & $88 \pm 20$ & $66 \pm 17^{*}$ \\
Serine & $70 \pm 16$ & $52 \pm 12^{*}$ \\
Glycine & $155 \pm 10$ & $109 \pm 9^{*}$ \\
Alanine & $158 \pm 25$ & $108 \pm 15^{*}$ \\
Valine & $109 \pm 21$ & $104 \pm 15$ \\
Leucine & $63 \pm 13$ & $70 \pm 9$ \\
Isoleucine & $35 \pm 12$ & $36 \pm 10$ \\
Phenylalanine & $64 \pm 6$ & $45 \pm 9^{*}$ \\
Tyrosine & $87 \pm 10$ & $70 \pm 8^{*}$ \\
Lysine & $105 \pm 20$ & $85 \pm 20^{*}$ \\
Arginine & $63 \pm 10$ & $47 \pm 6^{*}$ \\
\hline
\end{tabular}

* Significantly different from basal values for the same subjects $(\mathrm{p}<() \cdot() 5$ or less $)$. reached the same values as in the controls. This result would suggest that even in the suppressed state of insulin secretion the metabolism of the hormone may be impaired in cirrhosis, probably because of decreased hepatic degradation or secondary to portal-systemic shunting. This interpretation is supported by results, which show a reduced c-peptide insulin ratio. ${ }^{17}$

Glucagon concentrations are raised in advanced cirrhosis of the liver resulting from an increase of the so called pancreatic glucagon. ${ }^{21}$ In controls and in patients with cirrhosis glucagon concentrations were reduced by somatostatin, but the concentrations remained raised in the cirrhotic subjects. It is known that glucagon is degraded in the liver but substantial metabolism occurs in the kidneys as well. ${ }^{22}$ Under the influence of somatostatin a normal glucagon concentration could therefore be expected in cirrhotics, as somatostatin inhibits the pancreatic secretion of the hormone. ${ }^{11}$ The failure of somatostatin to reduce raised glucagon concentrations to normal may be caused by an altered secretion of the hormone as suggested by Sherwin et al. ${ }^{23}$

Infusion of somatostatin improved in part the deranged plasma amino acid pattern in cirrhosis in that the concentrations of the branched chain amino acids and of threonine, serine, glycine alanine, lysine, and arginine increased. The increase of the gluconeogenic amino acids may be because of the reduction of hepatic uptake and metabolism by the liver when glucagon concentrations are lowered by somatostatin, as it has been shown that suppression of glucagon secretion impairs hepatic extraction of these amino acids. ${ }^{24}$

The concomitant infusion of somatostatin and glucagon led to a decrease of the insulin/glucagon ratio from 3.55 to 0.34 in patients with cirrhosis; this reduced insulin/glucagon ratio would favour the movement of plasma amino acids into the gluconeogenic pathways ${ }^{25}$ and may therefore be responsible for the resulting decrease in plasma amino acid concentrations. It is notable that the rise in plasma glucagon concentrations during the infusion of somatostatin plus glucagon also decreased the aromatic amino acid concentrations. These results suggest that hyperglucagonaemia may not be responsible for the increased concentrations of the aromatic amino acids as suggested by James et al. ${ }^{9}$ Our interpretation is in accordance with data from the literature which have shown that glucagon stimulated the metabolism of the aromatic amino acids $^{26}$ and induced hypoaminoacidaemia. ${ }^{27-29}$

The combined infusion of somatostatin plus insulin in cirrhosis prevented the increase of the branched chain amino acids normally associated with somatostatin administration. It is therefore 
possible that the increase of these amino acids induced by somatostatin alone may be the result of a decrease in the insulin concentration. Some data support this hypothesis. The primary site of branched chain amino acid metabolism is the muscle and fat tissue, and amino acid entry is regulated by the insulin levels. ${ }^{9}$ In addition, in uncontrolled Type I diabetes mellitus branched chain amino acid concentrations are high ${ }^{30}$ and are corrected by insulin treatment. ${ }^{31} 32$

In conclusion, the positive influence of somatostatin in improving the deranged plasma amino acid pattern normally found in cirrhotics may be because of its success in reducing raised insulin and glucagon concentrations. Other effects attributed to somatostatin (including inhibition of other hormone secretions), however, are possible causes and cannot be discarded at present.

\section{References}

1 Fischer JE, Rosen HM, Ebeid AM, James H, Keane JM, Soeters PB. The effect of normalization of plasma aminoacids on hepatic encephalopathy in man. Surgery 1976; 80: 77-91.

2 Morgan MY, Marshall AW, Milsom JP, Sherlock S. Plasma amino-acid patterns in liver disease. Gut 1982; 23: $362-70$.

3 Ganda OP, Ruderman NB. Muscle nitrogen metabolism in chronic hepatic insufficiency. Metabolism 1976; 25: 427-35.

4 Rosen HM, Yoshimura N, Hodgman JM, Fischer JE. Plasma amino acid patterns in hepatic encephalopathy of differing etiology. Gastroenterology 1977; 72: 483-7.

5 Marchesini G, Zoli M, Angiolini A, Dondi C, Bianchi FB, Pisi E. Muscle protein breakdown in liver cirrhosis and the role of altered carbohydrate metabolism. Hepatology 1981; 1: 294-9.

6 Munro HN, Fernstrom JD, Wurtmann RJ. Insulin, plasma aminoacid imbalance and hepatic coma. Lancet 1975; 1: 722-4.

7 Johnston DG, Alberti KGM, Faber OK, Binder C. Hyperinsulinism of hepatic cirrhosis: diminished degradation or hypersecretion? Lancet 1977; 1: 10-13.

8 Sherwin R, Yoshi P, Hendler R, Felig P, Conn HO. Hyperglucagonemia in Laennec's cirrhosis: the role of portal systemic shunting. $N$ Engl J Med 1974; 290: $239-42$.

9 James JE, Ziparo V, Jeppson B, Fischer JE. Hyperammonemia, plasma aminoacid imbalance and blood brain aminoacid transport: a unified theory of portal systemic encephalopathy. Lancet $1979 ; 1$ : 772-5.

10 Marchesini G, Forlani G, Zoli M et al. Insulin and glucagon levels in liver cirrhosis: relationship with plasma amino acid imbalance of chronic hepatic encephalopathy. Dig Dis Sci 1979; 24: 594-601.

11 Koerker DJ, Ruch W, Chideckel E, Palme J, Goodner CJ, Gale CC. Somatostatin: hypothalamic inhibitor of the endocrine pancreas. Science 1974; 184: 482-4.

12 Child CG, and Turcotte JG. In: Child CG, ed. The liver and portal hypertension. Philadelphia: Saunders, 1964: 50.

13 Wide L, Porath J. Radioimmunoassay of proteins with the use of sephadex coupled antibodies. Biochim Biophys Acta 1966; 130: 257-60.

14 Heding LG. Radioimmunological determination of human C-peptide in serum. Diabetologia 1975; 11: 541-8.

15 Faloona G, Unger R. Glucagon. In: Jaffe B, Behrmann $\mathrm{H}$, eds. Methods of hormone radioimmunoassay. New York and London: Academic Press, 1974: 317-30.

16 Soeters PB, Fischer JE. Insulin, glucagon, aminoacid imbalance and hepatic encephalopathy. Lancet 1976; 1: 880-2.

17 Smith-Laing GS, Sherlock S, Faber OK. Effects of spontaneous portal systemic shunting on insulin metabolism. Gastroenterology 1979; 76: 685-90.

18 Riggio $\mathrm{O}$, Merli $\mathrm{C}$, Cangiano $\mathrm{R}$ et al. Glucose intolerance in liver cirrhosis. Metabolism 1982; 31: 627-34.

19 Faber OK, Kehlet H, Madsbad S. Kinetics of human c-peptide in man. Diabetes 1978; 27: 207-9.

20 Katz AJ, Lindheimer DM, Mako ME, Rubenstein AH. Peripheral metabolism of insulin proinsulin and cpeptide in the pregnant rat. J Clin Invest 1975; 56: 1608-11.

21 Valverde I, Villanueva ML. Heterogenity of plasma immunoreactive glucagon. Metabolism 1976; 25: 13935 .

22 Lefebvre PJ, Luyckx AS. Effect of acute kidney exclusion of renal arteries on peripheral plasma glucagon levels and pancreatic glucagon production in the anesthetized dog. Metabolism 1975; 24: 1169-83.

23 Sherwin R, Fisher M, Besoff J, Snyder N, Hendler R, Conn HO, Felig P. Hyperglucagonemia in cirrhosis: altered secretion and sensitivity to glucagon. Gastroenterology 1978; 74: 1224-8.

24 Cherrington AD, Lacy WW, Chiasson JL. Effect of glucagon on glucose production during insulin deficiency in the dog. J Clin Invest 1978; 62: 664-77.

25 Unger RH. Glucagon physiology and pathophysiology. N Engl J Med 1971; 285: 443-9.

26 Haley CJ, Harper AE. Glucagon stimulation of phenylalanine metabolism. The effect of acute and chronic glucagon treatment. Metabolism 1982; 31: 524-32.

27 Lilienquist JE, Lewis SB, Cherrington AD, SinclairSmith BC, Lacy WW. Effects of pharmacological hyperglucagonemia on plasma amino acid concentrations in normal and diabetic man. Metabolism 1981; 30: $1195-9$.

28 Mallinson CN, Bloom SR, Warin AP. A glucagonoma syndrome. Lancet 1974; 2: 1-5.

29 Brodan V, Brodanova M, Andel M, Kuhn E. The effect of glucagon on free plasma amino acids in cirrhotics and healthy controls. Acta Hepatogastroenterol (Stuttg) 1978; 25: 23-29. 
30 Berger M, Zimmermann-Telschow A, Berchtold $\mathrm{P}$ et al. Blood amino acid levels in patients with insulin excess (functioning insulinoma) and insulin deficiency (diabetic ketosis). Metabolism 1978; 27: 793-9.

31 Carlsten A, Hallgren B, Jagenburg R. Amino acids and free fatty acids in plasma in diabetics. The effect of insulin on arterial levels. Acta Med Scand 1966; 179: 361-70.

32 Hanna AK, Zinman B, Nakhoda AF et al. Insulin, glucagon, and amino acids during glycemic control by the artificial pancreas in diabetic man. Metabolism 1980: 29: 321-2. 